DOI 10.37882/2500-3682.2021.03.13

\title{
СПЕЦИФИКА ЭКЗИСТЕНЦИАЛЬНЫХ ВЫБОРОВ ЛИЦ АСОЦИАЛЬНОЙ НАПРАВЛЕННОСТИ
}

\section{PARTICULARITY OF EXISTENTIAL CHOICES OF ASOCIAL ORIENTATED PERSONS}

\section{Z. Myasnikova}

Summary: The article is dedicated to studying of particularity of existential choices of asocial orientated persons. They were defined as people, convicted and serving a sentence in places of freedom deprivation.

The actuality of the article is defined by requirement in studying of the psychological problems, which a person, who violated the law and was placed into social isolation conditions, faces to. It's necessary to understand the particularity of person's choices for his or her successful adaptation and work organization with such people.

The aim of the article lies in research of life path and individual life experience of asocial orientated person for definition of his or her existential choices features.

As a base of empirical research convicted persons between the ages of 35 and 56 with higher education were chosen. The analysis was conducted via the author's own structured interview, made by the method of narrative analysis.

The author came to the conclusion that the particularity of existential choices of asocial orientated persons is determined by the fact, how the person's childhood and youth were going, what the social environment, parenting, educational level, professional engagement and satisfaction with work conditions were.

Also the author underlined requirement in further practical work and analysis in research area because the data, obtained in the course of the experiment, can't pretend to be completely accurate.

Keywords: existential choice, social isolation, behavior particular qualities, asocial orientation, life decisions, motivation, narrative analysis, reflection, individual life experience, morality, value orientations.
$\mathrm{B}$ настоящее время довольно популярным среди исследователей экзистенциально ориентированного научного поля становится вопрос изучения осмысленности жизни, свободы принятия решений и особенностей экзистенциального выбора личности в целом. Среди исследователей экзистенциального поля выделяются учения Л. Бинсвангера, И. Ялома, В. Франкла, Р. Мэя, С. Мадди, А. Ленгле и др. Среди отечественных исследователей, разделяющих экзистенциальные принципы, возможно отметить Рубинштейна С.Л., Леонтьева Д.А., Василюка Ф.Е., Братченко С.Л. Согласно их определению о выбирающей личности, «человек сам ответственен за выбор своего существования» [2]. Таким образом, исследователями-экзистенциалистами выбором существова-
Мясникова Зоя Вячеславовна

Аспирант, Тихоокеанский государственный университет myasnikovazoya@yandex.ru

Аннотация: Статья посвящена изучению специфики экзистенциальных выборов лиц с асоциальной направленностью в поведении. Данными лицами были определены люди, осужденные и отбывающие наказание в местах лишения свободы.

Актуальность темы статьи определяется потребностью изучения психологических проблем, с которыми сталкивается личность, нарушившая нормы закона и помещенная в условия социальной изоляции. Для успешной адаптации и организации работы с такими лицами необходимо понимать специфику выборов личности.

Цель статьи заключается в исследовании жизненного пути и индивидуального жизненного опыта асоциальной личности для определения особенностей ее экзистенциального выбора.

В качестве базы эмпирического исследования были отобраны осужденные в возрасте от 35 до 56 лет, имеющие высшее образование. Анализ проводился посредством авторского структурированного интервью, составленного по методу нарративного анализа.

Автор пришел к выводу, что специфика экзистенциальных выборов лиц асоциальной направленности во многом определяется тем, как протекало детство и юность личности, каким было социальное окружение, родительское воспитание, уровень образования, профессиональная вовлеченность и удовлетворенность условиями труда.

Также автор обозначил потребность дальнейшей практической работы и анализа в исследуемой сфере, поскольку полученные им в ходе эксперимента данные не могут претендовать на абсолютную точность.

Ключевые слова: экзистенциальный выбор, социальная изоляция, особенности поведения, асоциальная направленность, жизненные решения, мотивация, нарративный анализ, рефлексия, индивидуальный жизненный опыт, нравственность, ценностные ориентации.

ния определяется экзистенциальный выбор, при котором личность осознанно выбирает, каким образом ей существовать (жить в мире), после чего ею совершается поступок.

Особый научно-практический интерес для исследования представляет изучение особенностей поведения и экзистенциального выбора лиц, преступивших нормы закона, имеющих поведенческие установки асоциальной направленности. В рамках данной статьи под лицами асоциальной направленности подразумеваются люди, осужденные и отбывающие наказание в местах лишения свободы. 
Актуальность темы статьи обусловлена потребностью изучения психологических проблем, с которыми сталкивается личность, преступившая закон и находящаяся в местах социальной изоляции, поскольку для организации жизнедеятельности в исправительном учреждении и разработки и применения адекватных методов психологической работы с ними требуется учет особых условий среды, в которой они оказались, и понимание специфики их выборов. Предположительно, экзистенциальная природа выбора личности обусловливает ее правовое поведение, социальное либо асоциальное.

Начнем с того, что экзистенция отождествляет жизнь личности, наполненную смыслом, в которой есть место для глубоких чувств, желаний, стремлений, собственных жизненных решений, поступков и выборов [1]. Такая жизнь может показаться трудной, но она реальная, полная смысла, а значит, полноценная, в которой приоритетное значение имеет духовное начало человека. Несоответствие экзистенции порождает у личности экзистенциальные проблемы, связанные с ощущением несоответствия той истинно человеческой жизни, к которой должен стремиться человек [6], вследствие чего у него наступает стадия разочарования, появляются мысли о потенциальных возможностях получения желаемого любыми способами, пусть и противоправными.

Так, интересным для исследования экзистенциальных проблем личности представляется экзистенциальный анализ, разработанный последователем В. Франкла - А. Лэнгле. Согласно его теории, структурная модель экзистенциального анализа объединяет четыре фундаментальные мотивации личности, необходимые и важные условия для наполненности жизни смыслом:

1. Первое условие - желание жить, находиться в мире. Данное условие зависит от того, обладает ли личность опорой и защитой, имеет ли она пространство для жизни.

2. Второе условие - любовь к жизни. Означает потребность в удовлетворенности условиями своей жизни, а именно: способность устанавливать и поддерживать дружественные и близкие отношения с людьми, ощущение внутреннего и внешнего комфорта.

3. Третье условие - признание права быть собой. Указывает на важность не только принятия личностью мира таким, каков он есть, но и потребность в осознании того, что и мир, и окружающие воспринимают тебя так же.

4. Четвертое условие - осознание важности своих действий, поступков. Демонстрирует процесс поиска смыслов жизни, чего-то важного и полезного для личности и осознания личностью своей собственной важности и полезности для окружающих [7].
При несоблюдении любого из условий, когда человек не находит смысла жизни, наступает чувство собственной никчемности, ненужности, отчаяния и разочарования, определенные В. Франклом как «состояние экзистенциального вакуума» [7]. При нахождении же человеком смысла своей жизни, он способен на самоотдачу. Так, человек, имея множественную природу своих поступков, способен выбирать, в каком мире существовать, к какому состоянию стремиться, и как следствие, обладая такими возможностями, он и несет ответственность за свои действия. Иными словами, речь идет об экзистенциальном выборе.

Опираясь на теорию А. Лэнгле, возможно предположить, что лица асоциальной направленности, совершая свои выборы, находятся в состоянии «экзистенциального вакуума», когда отмечается отсутствие либо неполноценность фундаментальных мотиваций, что и приводит к отклонениям в правовом поведении личности.

Для сбора эмпирических данных по проблеме выделения специфики экзистенциальных выборов лиц асоциальной направленности был выбран метод нарративного анализа. Данный метод был предложен испытуемым в формате письменного структурированного интервью, которое содержало модули и блоки, совокупность развернутых ответов на которые позволяет исследователю проследить наиболее значимые события жизненного пути личности. Так, блоки первого модуля предполагают развернутые ответы на вопросы относительно себя (цель жизни, ценностные ориентации, семья, профессиональная состоятельность), блоки второго модуля отвечают за истории жизни (негативные и позитивные события, переломные моменты в жизни личности), блоки третьего модуля раскрывают опыт личности (из детства, юности, «точки бифуркации»), блоки четвертого модуля содержат информацию о важных жизненных решениях и выборах личности.

В качестве экспериментальной группы были отобраны осужденные и отбывающие наказание женщины и мужчины в возрасте от 35 до 56 лет, в количестве 10 человек, имеющие высшее образование.

В ходе исследования материалы интервью прошли обработку, которая заключалась в удалении ненарративных данных. Это позволило нам убрать из текста интервью что-то не совсем важное, имеющее не прямое отношение к событиям, лишние детали. Далее были выделены дескрипторы, которые наиболее точно определяют содержание нарративного интервью.

Так, по первому модулю были выбраны дескрипторы: цель жизни, смысл жизни, жизненная ценность, семья, друзья, профессия, любимое дело. По второму модулю дескрипторы: жизненный урок, зависимость, раскаяние, 
истина. Согласно описаниям из третьего модуля были определены дескрипторы: бескорыстие, искренность, свобода, независимость, ответственность, осознание. Для четвертого модуля были определены дескрипторы: реализация, мечта, материальная стабильность, благодарность, возможность.

Выделенные из нарративного интервью дескрипторы, по нашим наблюдениям, совпали с фундаментальными мотивациями (условиями), предложенными А. Лэнгле в структурной модели экзистенциального анализа.

Так, первая мотивация - желание жить, находиться в мире - сопряжена с дескрипторами первого модуля интервью: цель жизни, смысл жизни, жизненная ценность, семья, друзья, профессия, любимое дело.

Вторая мотивация - любовь к жизни - имеет отношение к дескрипторам второго модуля интервью: жизненный урок, зависимость, раскаяние, истина.

Третья мотивация - признание права быть собой подразумевает применение дескрипторов третьего модуля интервью: бескорыстие, искренность, свобода, независимость, ответственность, осознание.

Четвертая мотивация - осознание важности своих действий, поступков - сопряжена с дескрипторами четвертого модуля интервью: реализация, мечта, материальная стабильность, благодарность, возможность.

Помимо выделения закономерности - совпадения фундаментальных мотиваций личности с дескрипторами интервью - в результате нарративного анализа проводилась структурная обработка данных интервью. Следует подчеркнуть, что именно этот этап анализа историй жизни респондентов вызвал наибольшие трудности с их интерпретацией. Это связано с тем, что до настоящего времени не определены единые правила и алгоритмы, которые бы позволяли исследователю объективно и некритически переходить от этапа сбора данных до этапа их анализа.

В процессе обработки данных из каждого интервью были удалены все ненарративные элементы, лишние детали, которые перегружают истории, отвлекая от главной мысли. Далее мы описывали этапы жизненного пути личности по каждому интервью, что позволило нам полноценно проследить биографический процесс и жизненный опыт личности. Практически у всех респондентов (8 человек) жизнь представлена в качестве двух половинок - до заключения, на свободе, и после, в условиях социальной изоляции. И только у 2 человек жизненный опыт был отмечен в качестве редуцированного к опыту из детства. Это позволило нам отметить рефлексивную направленность, заставляющую личность вновь и вновь переживать события из далекого прошлого.

На следующем этапе обработки полученных нарративных данных в интервью были возвращены удаленные ранее ненарративные элементы повествования. Это дало нам возможность определить их функцию в повествовании, а именно: на что ориентируется личность в своем рассказе о собственной жизни, оправдывается ли за свои поступки и выборы, пытается ли что-то доказать, подчеркнуть и т.д.

Далее, ознакомившись с историями жизни, опытом респондентов, имея раскрытую картину их возможностей, как реализованных, так и упущенных, через весь их жизненный путь, мы определяли особенности экзистенциального выбора респондентов с асоциальной направленностью в поведении.

Так, опираясь на дескрипторы из первого модуля, мы определили в каком ключе, позитивном или негативном, личность самоидентифицирует себя, удовлетворена ли она своей целью, профессией, семейным положением, что определяет в качестве жизненных ценностей, к кому испытывает неприязнь или симпатию.

Дескрипторы второго модуля позволили нам определить, насколько осознанно личность извлекает жизненные уроки, раскаивается ли в своих поступках, в чем находит истину, зависима ли от событий и окружающих.

Дескрипторы третьего модуля направили нас к опыту прошлого, а также к событиям, иллюстрирующим позитивный наивысший подъем и указали на то, что практически у всех респондентов в воспоминаниях о детстве и юности возникает эмоциональный импульс положительной направленности. Другими словами, из интервью становится очевидным, что респонденты ценят опыты прошлого, все негативное воспринимается ими как жизненные уроки. С другой стороны, также наблюдается осознание ими упущенных возможностей, ответственность либо отказ от нее за то, что их жизненные опыты сложились именно так, а не иначе.

Дескрипторы четвертого модуля, выявленные при описании жизненно важного решения, жизненного выбора респондентов, помогли раскрыть их стремление к обретению свободы, переоценку ценностей, возвращению к новой жизни с вынесенными уроками из старой. Как правило, респонденты более подробно описывали именно четвертый модуль, который также отражал их планы на жизнь, стремления реализовать себя после освобождения из места лишения свободы.

Так, мы пришли к заключению, что специфика экзистенциальных выборов лиц асоциальной направленности во многом определяется тем, находилась ли 
личность в моменты выборов в «состоянии экзистенциального вакуума». Важным считается и то, как протекало детство и юность личности, каким было социальное окружение, родительское воспитание, уровень образования, профессиональная вовлеченность и удовлетворенность условиями труда. Если хотя бы некоторые из перечисленных факторов влияния имели место в жизни личности, отметим большую вероятность того, что впоследствии они и привели к снижению уровня правового поведения личности.

Однако, полученные данные не могут претендовать на абсолютную точность, все они требуют дальнейшей практической работы и анализа. Проведенные интервью стали для автора первичным опытом нарративного исследования и, по его мнению, могут быть очень полезны в работе практикующего психолога, поскольку позволяют оценить события жизненного пути личности по следующей системе: равновесие - нарушение равновесия - восстановление равновесия. Кроме того, в процессе описания своей истории жизни личность испытывает повышенную рефлексию и критичность в отношении своего опыта, что, в свою очередь, повышает активность личности и ее самостоятельность в процессе определения формата своей настоящей и будущей жизни. Все это, на наш взгляд, имеет видимый терапевтический эффект для личности, в особенности для той, которая находится в трудной жизненной ситуации (осуждение и наказание, социальная изоляция, потребность в адаптации к новым условиям жизни и т.д.).

\section{ЛИТЕРАТУРА}

1. Бербаева И.Д. Психологические детерминанты дезадаптации личности в условиях изоляции: автореф... дис. канд. псих. наук. - Хабаровск, 2004.

2. Братченко С.Л. Экзистенциально-гуманистический подход в психологии и психотерапии / С.Л. Братченко // Психол. газ. «Иматон». - 1997. - № 1. - С. 7.

3. Василюк Ф.Е. Психотехника выбора // Психология с человеческим лицом: Гуманистическая перспектива в постсоветской психологии / под ред. Д.А. Леонтьева. - М.: Смысл, 1997. - 330 с.

4. Дружинин В.Н. Варианты жизни: очерки экзистенциальной психологии. М.: ПЕР (Э; СПб.: ИМАТОН-М, 2000. - 214 с.

5. Иванченко Е.С., Подлиняев 0.Л. Специфика экзистенциальных качеств личности курсантов в образовательной организации МВД РФ / Е.С. Иванченко, 0.Л. Подлиняев // Научный журнал «Дискурс». Психологические науки. - 2019. - № 4 (30). - с. 87-93.

6. Кокоева Р.Т., Багаева 3.Г., Дзагоев С.Г., Кесаева И.М., Лисовина В.В. Актуальные проблемы экзистенциальных категорий в современной психологии / Р.Т. Кокоева, З.Г. Багаева, С.Г. Дзагоев, И.М. Кесаева, В.В. Лисовина / [Электронный ресурс] // Фундаментальные исследования. - 2014. - № 6(6). C. 1307-1309. - Режим доступа: http://fundamental-research.ru/ru/article/view?id=34335

7. Лэнгле А. Экзистенциально-аналитическая теория личности. - М.: Генезис, 2005. - 159 c.

(с) Мясникова Зоя Вячеславовна (myasnikovazoya@yandex.ru). 